\title{
Characteristics of injuries to the cervical spine and spinal cord in polytrauma patient population: experience from a regional trauma unit
}

\author{
VSSV Prasad*,1, A Schwartz ${ }^{1}$, R Bhutani $^{1}$, PW Sharkey ${ }^{2}$ and ML Schwartz ${ }^{1}$ \\ ${ }^{1}$ Department of Neurosurgery, Sunnybrook Health Sciences Center, Toronto, Ontario, Canada; ${ }^{2}$ Trauma Program, \\ Sunnybrook Health Sciences Center, Toronto, Ontario, Canada
}

\begin{abstract}
Study design: Retrospective analysis of a prospectively collected trauma database of a Level 1 (tertiary) trauma center.

Objective: To define the features of the cervical spinal injuries in polytrauma population admitted to the regional trauma unit.

Setting: Canada, Ontario Province, Toronto, Sunnybrook Health Sciences Center.

Methods: All trauma admissions between 1987 and 1996 entered prospectively into a trauma registry database were studied for incidence, demographic and epidemiological details of cervical spine (cord and column) injuries.

Results: A total of 468 patients $(66 \%$ male) with cervical spinal injury (CSI) from 1198 spinal injuries admitted to the regional trauma center were identified. Seventy-five per cent of the CSI involved were aged less than 50 years; nearly 30\% were in the third decade alone. Overall, the commonest spinal level injured was C2 $(27 \%)$ followed by C5 $(22 \%)$. Older population (above 60 years of age) had $\mathrm{C} 1+2$ involved more often than the young $(P=0.02)$. Motor vehicular crashes (MVC) accounted for $71 \%$, followed by pedestrian trauma $(10 \%)$, sport injuries (7\%). Spinal cord injury (SCI) was noted in $27 \%$; complete in $16 \%$ and incomplete in $11 \%$ and more frequently at $\mathrm{C} 4$ or $\mathrm{C} 5$ level compared with $\mathrm{C} 1, \mathrm{C} 2$ $(P<0.00001)$; the former level had more often a complete SCI $(P=0.06)$. Though MVC produced $74 \%$ of SCI, only $27 \%$ had neurological deficits. Recreational trauma produced SCI in $45 \%$, motor cycle crashes (MCC) in $37 \%$ and a rear passenger in $\mathrm{MVC}$ in $34 \%$ that was complete in $78 \%, 71 \%$ and $73 \%$ respectively. Front seat passenger and driver in MVC had a C5 level injury while a rear seat passenger had at $\mathrm{C} 4(P<0.001)$. The $\mathrm{C} 1$ level injury had high association with severe and life threatening head and neck and facial injuries compared with the more frequently injured spinal levels; either C2 $(P=0.03)$ or C5 $(P=0.004)$. Similarly $\mathrm{C} 1$ injuries had higher ISS compared with C2 $(P<0.0001)$ and C5 $(P<0.008)$.

Conclusions: C2 was the commonest fractured spine while SCI was more frequent at C5. Older and pedestrian population had higher incidences of injuries at C1 and C2. Sport and MCC resulted in severe SCI. The level of spine injured was different between a front and a rear seat occupant in $\mathrm{MVC}$.
\end{abstract}

Keywords: cervical spine; epidemiology; prevention; spinal fractures; spinal cord injury

\section{Introduction}

The prevalence and incidence of spinal injuries vary with time and place. In North America, an average of 25-30 million sustain SCI annually, ${ }^{1}$ with a 1-year mortality rate of $28 \%$ and $14 \%$, for complete and incomplete SCI, respectively. ${ }^{2}$ However, population based and hospital based studies differ in the true incidence of spinal injuries and the epidemiology also varies significantly. ${ }^{3}$ The life expectancy, frequency of complications, cost for treatment and potential for rehabilitation for a SCI person depends on the age, the

*Correspondence: Dr VSSV Prasad, Department of Neurosurgery, LSU-Medical Center, 1501, Kings Highway, Shreveport, Louisiana, LA 71170-3932, USA anatomical location of the spinal injury and the severity of the spinal cord injury. $2,4,5$

The National SCI Statistical Center published a prevalence of approximately 200000 and an incidence of about 10000 patients per year; ${ }^{6}$ more than half of them are cervical SCI. ${ }^{7}$ The National Head and Spinal Cord Injury Survey estimated the annual incidence of cervical SCI with quadriplegia in the United States at 5 per $100000 .{ }^{8}$ Lifetime medical costs in 1982 US dollars for partial or complete quadriplegia varied between $\$ 760000$ and $\$ 940000$, resulting in an annual cost of 7.6-9.4 billion dollars. ${ }^{9}$ Studies of the nonsurvivors spinal injury suggest that the problem of neck injury is more severe with $25 \%$ to $40 \%$ pre- 
admission mortality. ${ }^{10}$ The study of the epidemiological factors is expected to provide adequate and useful information, pertinent to the population studied, for prevention of spinal injuries.

\section{Materials and methods}

Sunnybrook Health Sciences Center (SHSC) is the principal Level I trauma center (tertiary) in the province of Ontario, serving the population of Toronto and Southern Ontario, Canada with annual trauma census of about 650 cases. Nearly $70 \%$ of all spinal injuries and spinal cord injuries reach SHSC and patients are received from all over Southern Ontario and from all other hospitals. The majority of these are injured in vehicular crashes. Trauma assessment follows standard advanced trauma life support (ATLS) guidelines with a trauma team leader (a general surgeon, emergency physician, anesthetist) and other associates. All injuries are identified and coded. A standardized trauma assessment form is utilized in data entry. ${ }^{11}$ These data are collected prospectively, entered into injury database and then electronically entered into, and coded in computerized databases. ${ }^{12}$ For the present study, we retrospectively reviewed this data for all trauma patients admitted and treated between 1987 and 1996. There were a total of 1197 cases (24\% of total multi-trauma admissions) with spinal injury. As part of the trauma protocol, the whole spine is screened by radiographs in all multi-trauma individuals. This includes three views for cervical spine; anteroposterior, lateral with swimmers and an open mouth view for odontoid. Classification of injury according to ICD-9 CM (international Classification of Diseases, version 9 with Clinical Modifications) in combination with Abbreviated Injury Scale (AIS) scores were used for spinal (column and cord) injury description. The single most responsible spinal level was identified and the data was analyzed based on this localization.

\section{Results}

A total of 468 patients with cervical spinal injury from 1198 spinal injuries admitted to the regional trauma center between 1986 and 1997 were identified. Male gender constituted 66\%. Seventyfive per cent of the CSI involved a young population aged less than 50 years. Nearly $30 \%$ were in the third decade with $16 \%$ each in 2 nd and 4 th decades. The commonest spinal level injured was C2 $(27 \%)$ followed by C5 $(22 \%)$. Traffic accidents accounted for $71 \%$, followed by pedestrian trauma in $10 \%$, sport injuries in $7 \%$ and $5 \%$ each caused by fall and work related trauma. Spinal cord injury (SCI) was noted in 27\%; complete in $16 \%$ and incomplete in $11 \%$.

\section{Etiology of spinal injury in a given age group}

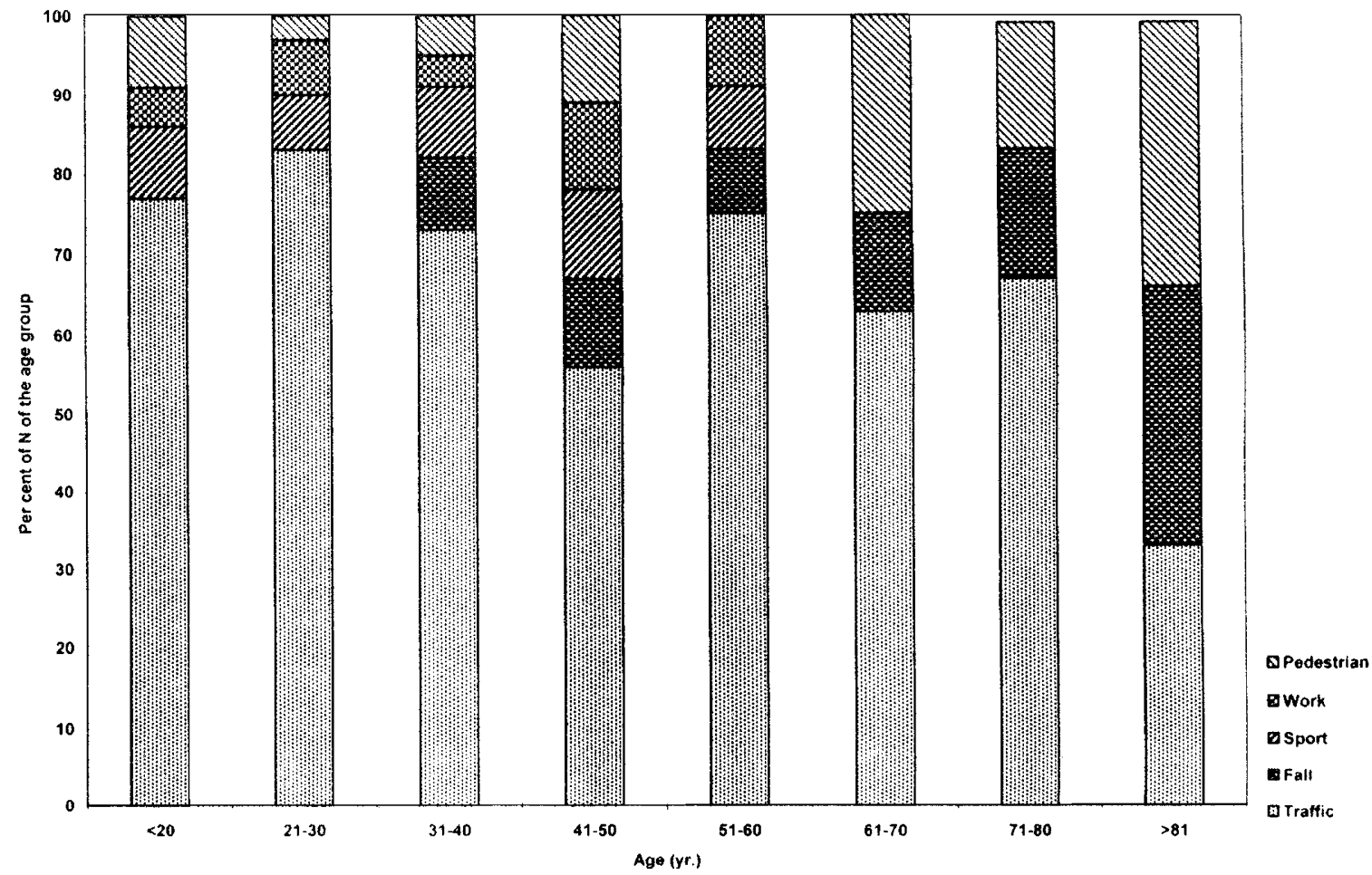

Figure 1 The etiology of cervical spinal injury in each decade of age. At any given age traffic was the most common cause except for the elderly, where falls, pedestrian injuries and traffic accidents were responsible for $1 / 3$ each 
The characteristics of the injuries in relation to the demographic and etiological factors were analyzed.

Age

Young population was the most affected. The involvement of $\mathrm{C} 1$ and $\mathrm{C} 2$ complex increased gradually with increasing age. After the sixth decade $2 / 3$ of spine trauma was at $\mathrm{C} 1 / 2$ compared with a younger population that had a lower cervical level of injury $(P<0.02)$. After 80 years, $75 \%$ of the patients had injury to upper cervical spine. At all the age groups MVC was the commonest cause of injury, except for patients aged above 80 years who had injuries due to MVC, fall and pedestrian trauma in equal proportion (Figure 1). Injury to the spinal cord decreased with increasing age. Most of the older population had an incomplete SCI. Nearly $90 \%$ of the SCI was complete in the 5th decade while only $33 \%$ had a complete SCI after the eighth decade.

\section{Gender}

The male, female ratio was 2.2 with a distinct difference in the etiology of spinal injuries. The proportion of females involved in front passenger MVC and pedestrian trauma was higher compared with males. Recreational, industrial and motor cycle trauma almost exclusively involved the male gender (Figure 2).

\section{Spinal level}

The commonest level of spinal column injury was $\mathrm{C} 2$ followed by C5. However, $46 \%$ of SCI involved the C5 level followed by $\mathrm{C} 4(22 \%)$ and C6 (11\%). Only $5 \%$ of $\mathrm{C} 2 \mathrm{had}$ an associated SCI while $57 \%$ of C5 injuries had suffered a neurological injury. SCI was observed in $57 \%$ of C4 and $24 \%$ of C6 level spinal trauma. A significantly higher proportion of SCI was complete at C4, 5 and C6. Nearly $50 \%$ of the complete SCI had a C5 level followed by $23 \%$ at $\mathrm{C} 4$. Thus, risk of SCI with $\mathrm{C} 4$ and $\mathrm{C} 5$ level injury was significantly high compared with injuries at $\mathrm{C} 1$ and $\mathrm{C} 2(P<0.00001$, Odds Ratio 5.23), as was the risk of the $\mathrm{C} 4$ and $\mathrm{C} 5 \mathrm{SCI}$ being a complete one $(P=0.06)$. At any level MVC was the commonest cause. However, there was some predilection for each etiology, next to MVC: $\mathrm{C} 1$ for pedestrian and recreational trauma, C2 for pedestrian trauma, C3 for fall, C4 for and $\mathrm{C} 7$ for recreational injuries (Figure 3).

\section{Etiology of spinal cord injury}

There were 124 patients with SCI; the commonest cause was MVC $(74 \%)$. However, only $28 \%$ of MVC had a SCI while $32 \%$ of fall and industrial accidents had an associated SCI. Among sport

\section{Etiology in either gender}

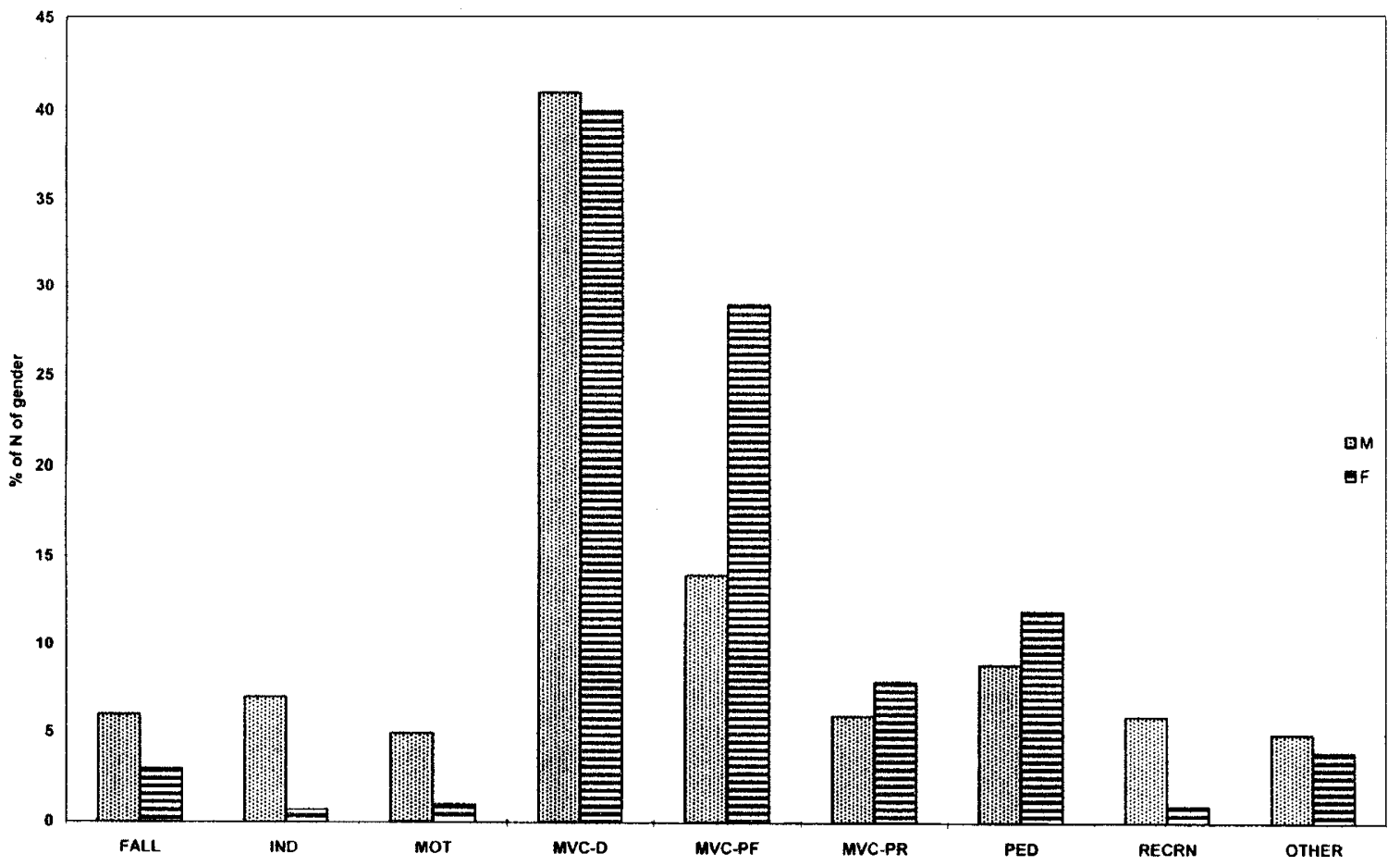

Figure 2 The gender differences in the etiology of spinal injuries. Work and recreational accidents were male dominated; while females had, higher proportion in the front passenger related MVC and pedestrian injuries 
injuries $22 \%$ had neurological injury and among them, $78 \%$ were complete. Sixty per cent of MVC inflicted SCI and $70 \%$ of SCI produced by fall and industrial trauma had complete neurological deficit. The proportionate severity of SCI is shown in Figure 4. The etiological preference for age groups is shown in Figure 5. MVC, sport and industrial trauma had a predilection for the youth, especially in the third decade of age; falls involved persons aged 40 years and above. Pedestrian trauma was predominant in the elderly $(>71$ years) and $22 \%$ involved 15-20 years age group. At any level MVC was the commonest cause. However, each etiology had some preferred spinal level (Figure 6): falls for $\mathrm{C} 5$, industrial accidents for $\mathrm{C} 6, \mathrm{C} 5$ and $\mathrm{C} 2, \mathrm{MVC}$ for $\mathrm{C} 2$ and $\mathrm{C} 5$, and pedestrian and recreational trauma for $\mathrm{C} 1+\mathrm{C} 2$ complex. Even in $\mathrm{MVC}$, the level of the spine involved differed by occupant position of the person (Figure 7); the rear passenger had a $\mathrm{C} 4$ level, while the driver or front passenger had suffered a C5 level injury $(P<0.0004)$.

\section{Severity of $S C I$}

There was SCI in 27\%; complete in $16 \%$ and incomplete in $11 \%$. The third decade of age accounted for $34 \%$ of the SCI and nearly $70 \%$ of all SCI involved persons under the age of 40 years. Only $17 \%$ were seen after the age of 70 years. With increasing age the incomplete SCI was more frequently observed. Sixty to ninety per cent of the SCI was complete in the young population. The commonest level of involvement was C5 (46\%) followed by C4 $(22 \%)$ with a predominantly complete deficit. Only $5 \%$ of $\mathrm{C} 2$ and $6 \%$ of $\mathrm{C} 7$ spinal injuries had neurological deficit (Figure 8). The proportion of complete SCI was also higher at C4 through C6 levels. Though MVC was the commonest cause of SCI the proportion of SCI caused by fall and industrial trauma was higher and $70 \%$ complete (Figure 4).

\section{Head and cervical spine trauma}

A low Glasgow Coma Scale (GCS) score was noticed with $\mathrm{C} 1$ injuries compared with any other level of spinal trauma. More than $60 \%$ cases with injuries at C4, 5, 6 and 7 had a GCS of 13 or more. Similarly more than $50 \%$ of poor GCS $(<5)$ had cervical spine trauma at $\mathrm{Cl}$ compared with the other commonly involved levels $\mathrm{C} 2$ $(P=0.03) \quad$ or $\quad$ C5 $\quad(P=0.004)$. A severe facial trauma also, had high association with $\mathrm{C} 1,2$ level spinal injury.

\section{Etiology of injury at each cervical level}

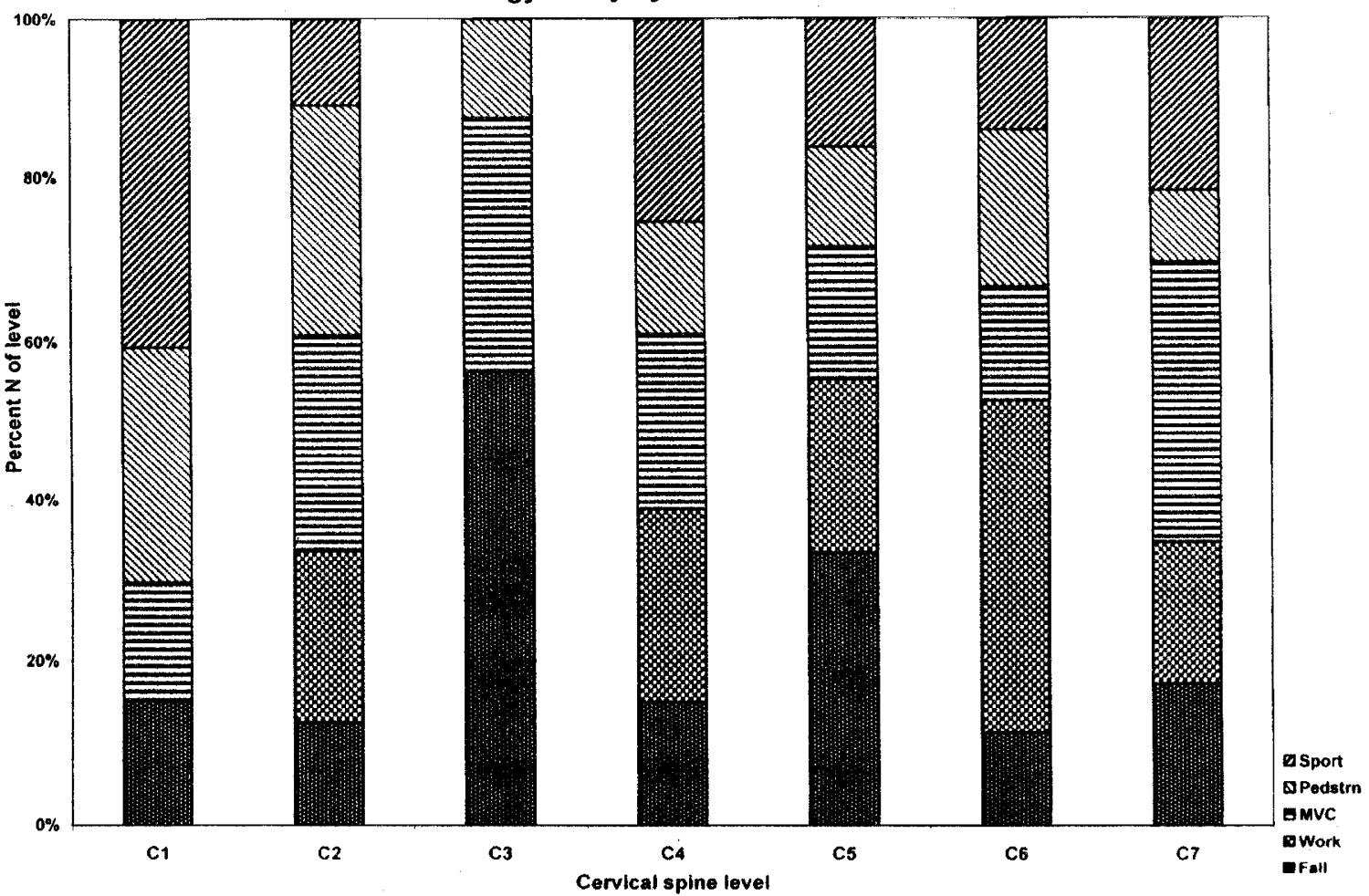

Figure 3 The involvement of each cervical spine level by a specific cause of spinal injury. Notable is the involvement of $\mathrm{C} 1$ in sport injuries, C3 in falls and C6 in work accidents. Sport injuries of C3 and work related trauma at C1 were not seen in our multitrauma population 
Etiology and severity of SCl

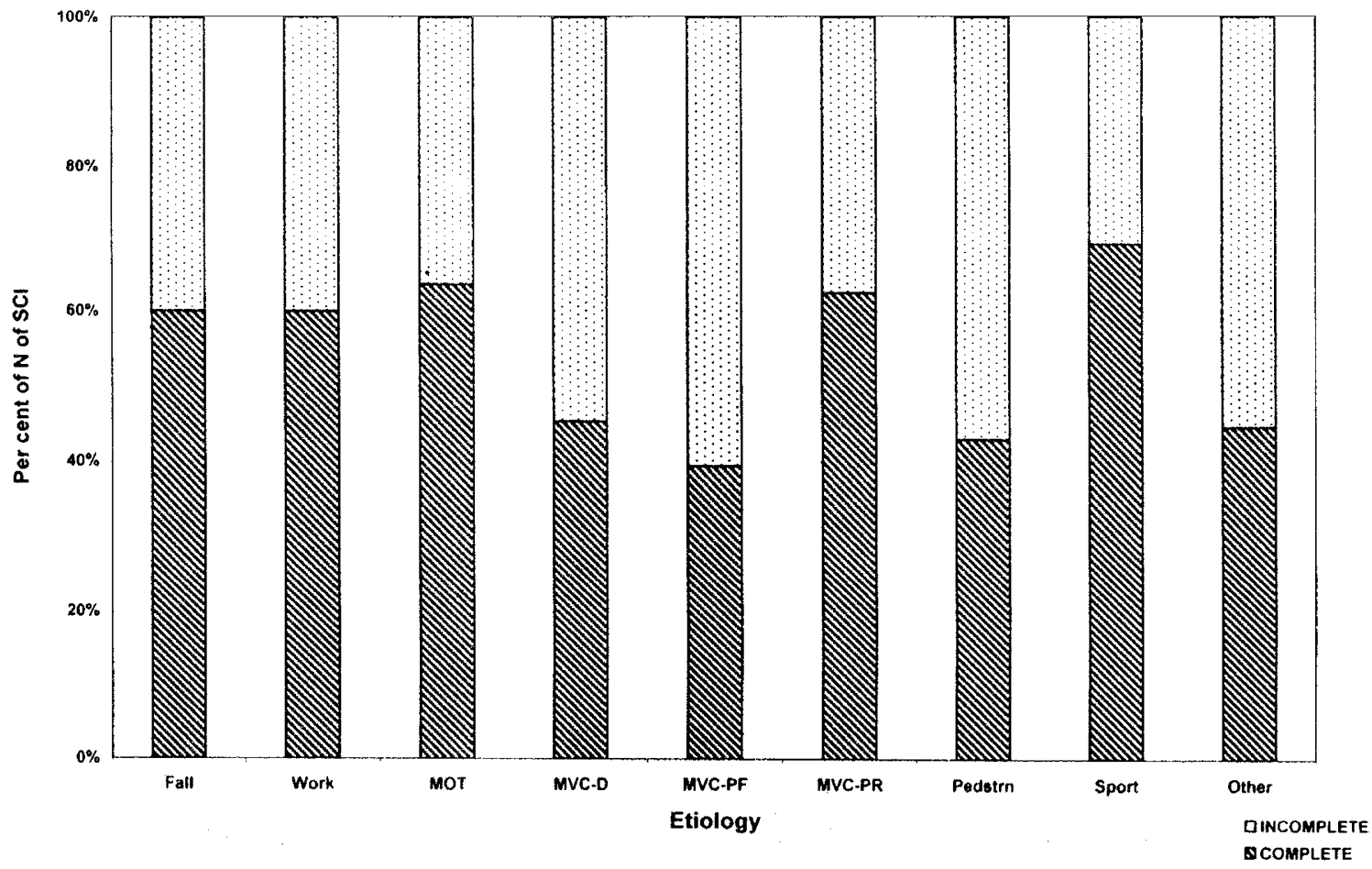

Figure 4 The severity of the spinal cord injury was not the same for all the causes. Though MVC (driver) was the commonest cause, majority was incomplete injuries. Nearly $2 / 3$ was complete injuries, in the case of motor cycle crash, sport injuries and also to some extent in the rear passenger involvement in a MVC

\section{Etiology by age groups}

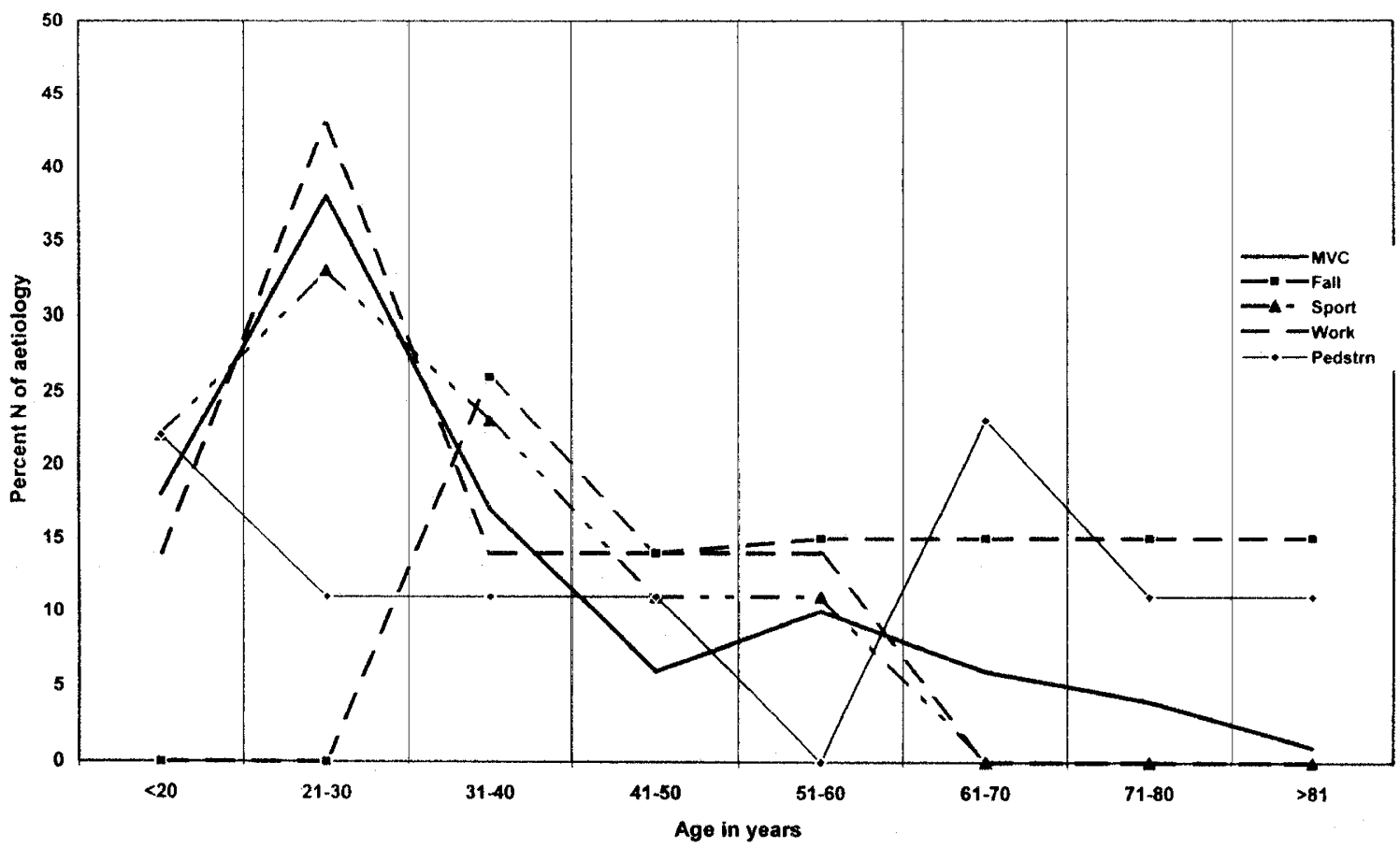

Figure 5 The etiology of spinal injuries had shown some predilection of age groups. Work, MVC and sport related trauma had involved the third decade, while pedestrian injuries had peaks during the 7 th and 2 nd decades. Fall related injuries started by third decade with a peak at the 4th to 5th decades 


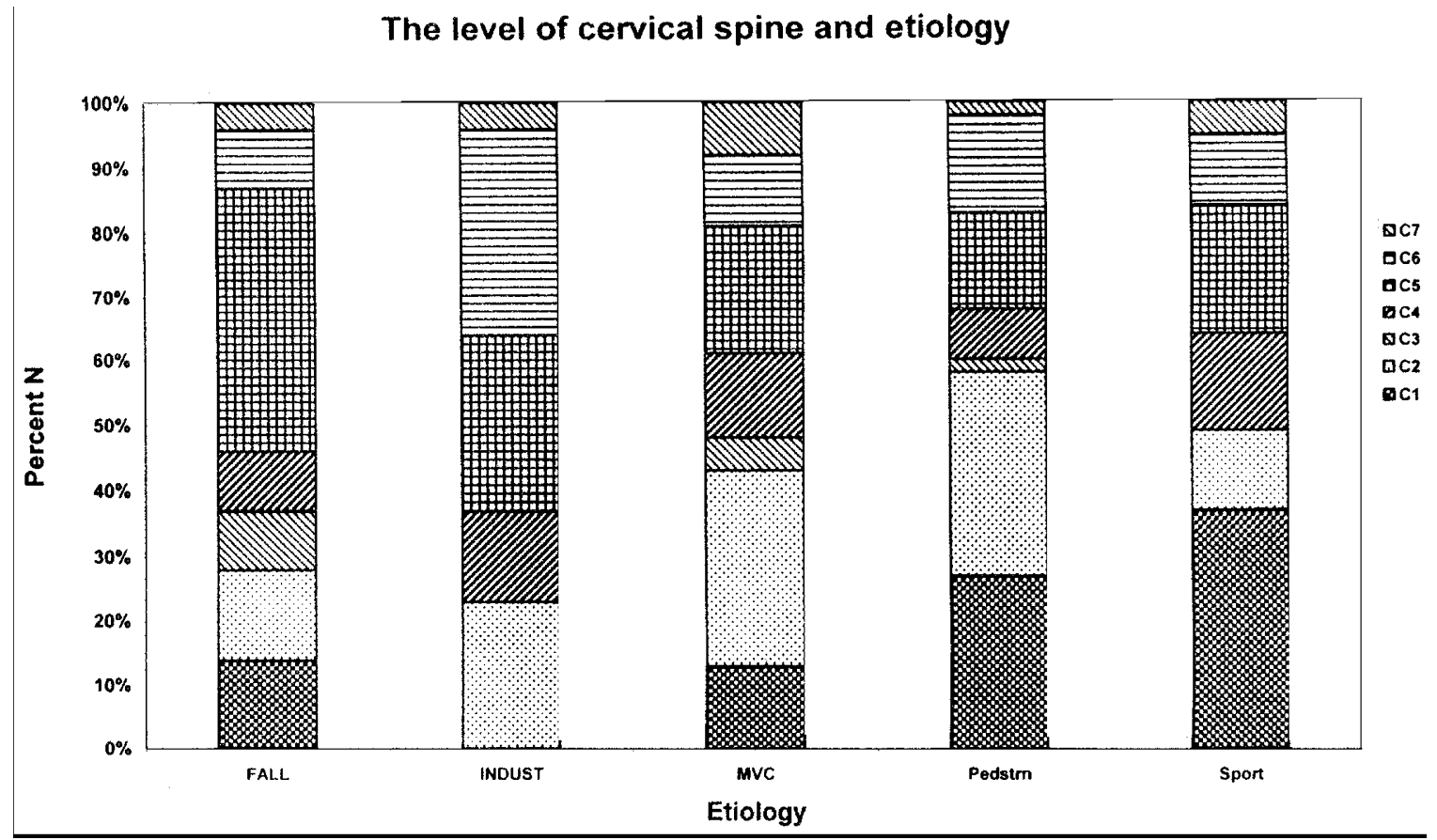

Figure 6 Each cause for spinal injury had different distribution of level of involvement. The commonest cause, MVC had C1 and $\mathrm{C} 2$ injury, as did the pedestrian injuries. The severity of industrial trauma is due to the involvement of lower cervical spine in majority of the instances

\section{Discussion}

Few reports differentiate cervical level spinal injury (SI) from spinal cord injury (SCI). We present the etiology and the other variables with reference to the occurrence of bony injury and SCI at the cervical spine. There are distinct differences between the two lesions. The anatomical level of SI or SCI had a good correlation with the etiology, age and other variables as described.

Many studies have reported a $52 \%$ to $68 \%$ incidence of cervical spinal injuries resulting from MVC. ${ }^{13-17}$ Cervical injuries in sports have been reported to have regional variation; football is the most recognized source of neck injuries in the US, surfing in California, rugby in New Zealand, snow mobiling in Canada. Other significant sources of cervical spine injury are swimming and diving accidents. Kewalramani reported that $18 \%$ of SCI was due to diving accidents. ${ }^{18}$

\section{Cervical spinal column injury}

The anatomical distribution of the CSI is not uniform in the literature, owing to the differences in the data collection. Significant differences have been reported between fatal and nonfatal trauma. ${ }^{16,19}$ Among survivors, several investigators have shown that, spinal injury is most common between C4 and C6 vertebrae, though controversy exists. ${ }^{14,20-22}$ In contrast, upper cervical injuries have been thought by many to be less common, and craniocervical injury with survival is reported only in case reports as recently as $1991 .^{13,23}$ Hadley et $a l^{10}$ suggested that $\mathrm{C} 2$ injuries comprise only $17 \%$ of cervical injuries among survivors admitted to a SCI service. Among upper cervical injuries occurring in survivors, fracture of $\mathrm{C} 1$, rupture of transverse ligament, rotary subluxation or dislocation of C1-2, odontoid fracture, and traumatic spondylolisthesis of the axis are the most common injuries. ${ }^{13}$ Macdonald et $a l^{18}$ reported that $\mathrm{C} 1-\mathrm{C} 2$ was the most frequently fractured cervical spinal segment, accounting for $27 \%$ of all patients. Ryan and Henderson ${ }^{24}$ suggested that the basis for these differences is related to age; they noted that $\mathrm{C} 2$ was the most frequent site of injury overall, that $\mathrm{C} 1$ and $\mathrm{C} 2$ injuries were frequently associated and that the C5-6 motion segment was the second most common. They also observed that $\mathrm{C} 2$ fractures increased with age, accounting for $43 \%$ of spinal fractures in people over the age of 50. In subjects, under the age of 50, injuries between $\mathrm{C} 5$ and C7 accounted for $66 \%$ of injuries, while C2 for $19 \%$. This is similar to our observation; younger population sustaining a lower spinal injury and older individuals (after sixth decade) had upper cervical level injury $(P<0.02)$.

\section{Cervical SCI}

Fatal accident surveys and postmortem investigations have reported that the most common site of cervical injury is the upper cervical spine. Alker et $a l^{25}$ reported that $31 \%$ of fatal neck injuries occurred at $\mathrm{C} 2,21 \%$ at 
The involvement of cervical spine in MVC

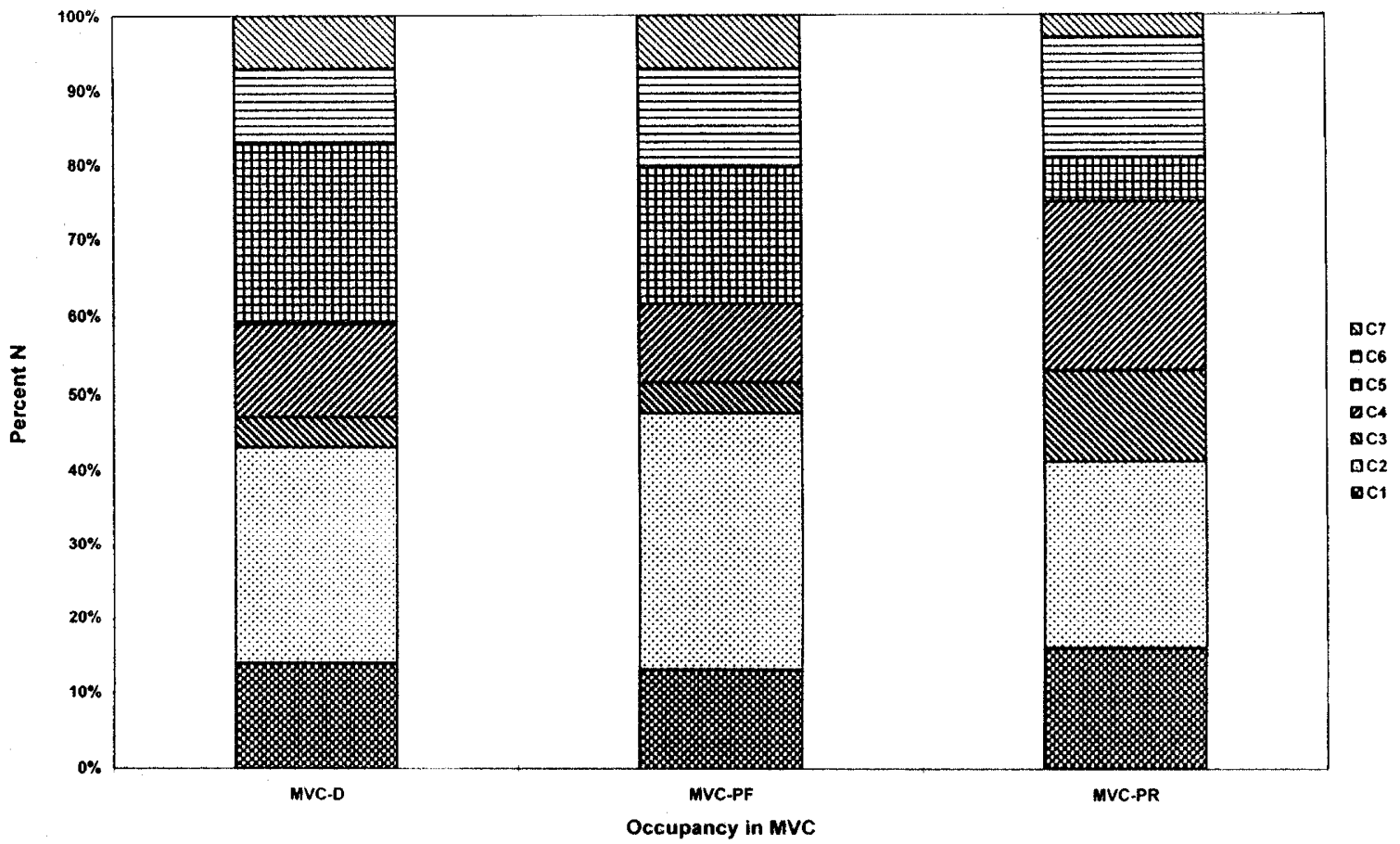

Figure 7 The level of cervical spine injured was different in the three different positions of the victim. A rear passenger in MVC differed from both the driver and front seat passenger, specifically in the involvement of $\mathrm{C} 3$ and $\mathrm{C} 4$. The front seat passenger and driver had almost similar distribution of the spinal level injured. This difference in the involvement of $\mathrm{C} 3$ and $\mathrm{C} 4 \mathrm{for}$ rear passenger, compared with either the driver or front passenger, was statistically significant. As a result, lower cervical spine injury and its associated SCI was higher in case of rear passenger. The contribution of seat belt restraints to this particular observation cannot be ruled out

$\mathrm{C} 1$ and $13 \%$ at the craniocervical junction. Bucholz et $a l^{26}$ also recorded a similar finding among the MVC fatalaties with neck injury; $38 \%$ occurred at $\mathrm{C} 2,33 \%$ at $\mathrm{C} 1$ and $13 \%$ at craniocervical junction. Burke et $\mathrm{al}^{14}$ in a hospital admission study, reported that C4-5 injuries accounted for $61 \%$ of all CSCI. Yoganandan et $a l^{22}$ utilizing the National Accident Sampling System (NASS) reported that the most common levels of the injury in survivors were C5 and C6. Portnoy et $a l^{21}$ also recorded a similar observation. Go et $a l^{27}$ in a clinical outcome study reported $\mathrm{C} 5$ as the most common neurological level of injury followed by $\mathrm{C} 4$, then C6. The figures in our study were $46 \%, 22 \%$ and $11 \%$ for $\mathrm{C} 5, \mathrm{C} 4$ and $\mathrm{C} 6$ respectively.

It appears from the literature review, that $\mathrm{C} 2$ level is the commonest for bony injury while $\mathrm{C} 5$ is for SCI. ${ }^{16,24,27}$ The majority of $\mathrm{C} 1+\mathrm{C} 2$ neurological lesions prove fatal and probably this is how they dominated the autopsy series. Overall, the C1-2 motion segment remains to be the commonest level for in trauma. ${ }^{3}$

The etiological preferences in cervical SCI have not been elucidated in literature so far. Burney et $a l^{28}$ identified in their study of SCI in North American Trauma Centers that cervical SCI occurred in $52 \%$ of multi-trauma population. They identified MVC, falls, pedestrian injuries and miscellaneous injuries to be associated with cervical SCI in $56 \%$ to $65 \%$. GSW and motor cycle accidents had lowest proportions of cervical SCI (30\% and 39\% respectively). However, the level of SCI in relation to the etiology was not reported in this study.

\section{Associated injuries and $M V C$ in $C S C I$}

Saboe et $a l^{29}$ did not identify any significant relationship between the type of associated injury and spine fracture level. It was observed in the present study that C1 fractures had a high association with severe head, neck trauma and facial injuries. The level of lower cervical spine injury differed by the occupancy of the victim in MVC. Driver and front passenger had almost identical lesions. The occurrence of $\mathrm{C} 4$ level trauma in rear passenger and C5 injury in driver/front passenger, in MVC $(P<0.0004)$ is difficult to explain. Probably this is related to the differences in the seat belt restraints used by them. Furthermore, $34 \%$ of rear passengers had SCI while $23 \%$ of front passengers and $27 \%$ of drivers had SCI. Majority of the SCI sustained by the rear passenger was complete $(73 \%)$ compared 


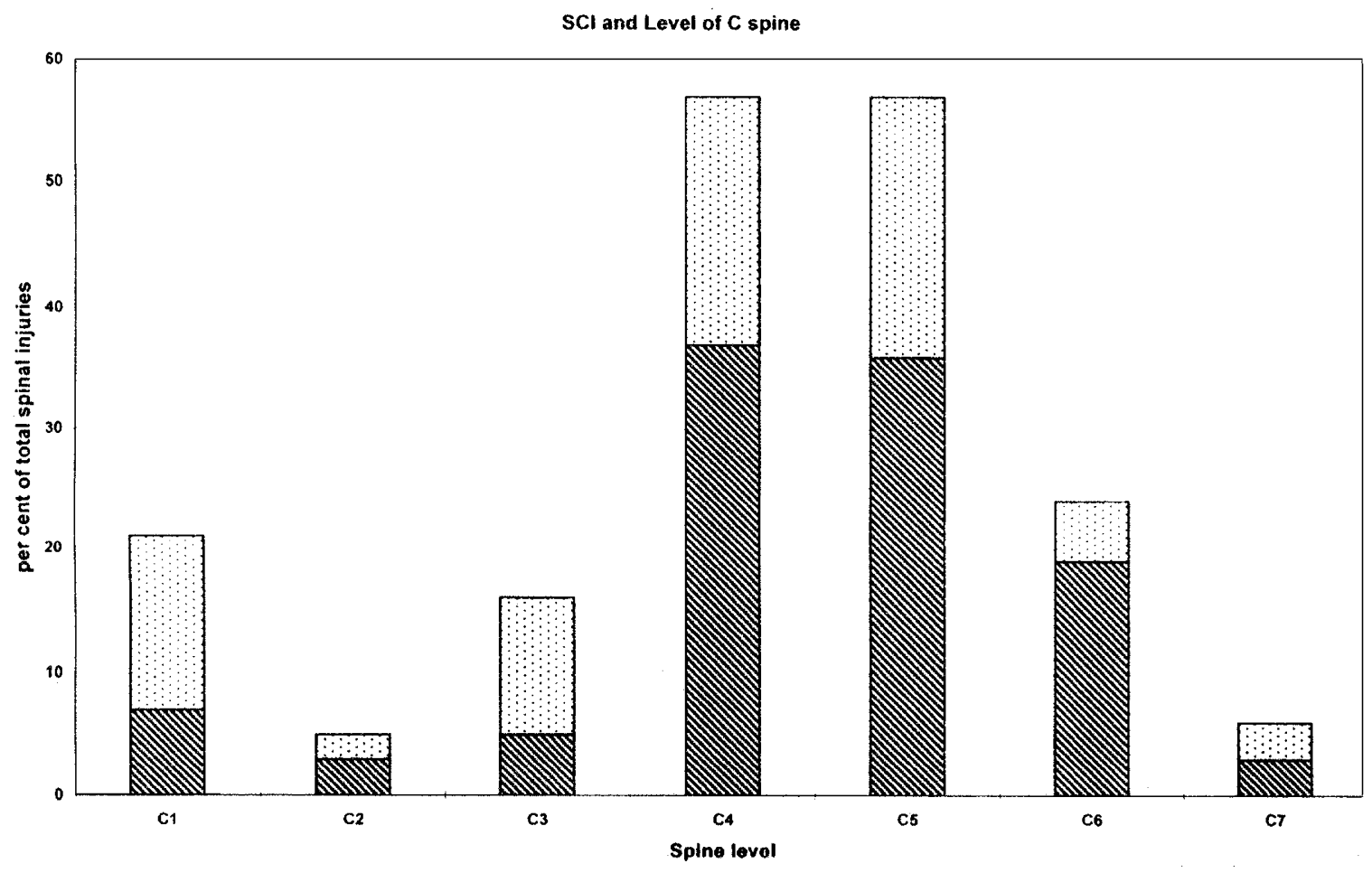

Figure 8 Spinal cord injury was mostly at C4 and C5. The other levels had less neurological damage. The occurrence of complete SCI was also higher at $\mathrm{C} 4$ and $\mathrm{C} 5$

with the other occupants $(50 \%$ and $56 \%$ for front passenger and drivers respectively). Hyper-flexion around the seat belt is known to be one of the causes $^{30}$ while specifics of the injuries depend upon the way in which the neck is flexed. ${ }^{31}$ The amount of neck flexion at the said level and the lap-shoulder belt restraint needs to be analyzed for correlation. The necessity for a head strap and/or airbags cannot be overemphasized in prevention of these injuries. It is especially important since, neurological deficit is more likely and the SCI is often a complete one at this spinal level. This also brings out the need to look for the $\mathrm{C} 1$ level trauma in severe facial and also head and neck injuries. It also appears, that the rear passengers in MVC require more attention in terms of preventive measures.

\section{Conclusions}

We attempted to define the features of cervical level injuries seen at a trauma center, in detail. MVC was the main cause. This might be skewed because of the selective nature of the population that reached the regional tertiary care trauma center. The identification of causes that result in severe disabling SCI may be useful in prevention. Specific target oriented prevention programs can be developed considering the different variables involved in the causation of severe injuries identified in the report. Work related SCI, falls and rear passenger MVC would require more attention in order to prevent severe cord injuries.

\section{References}

1 Bedbrook G, Clark WB. Thoracic spine injuries with spinal cord damage. J R Coll Edinb 1981; 26: 264-271.

2 Mesard L et al. Survival after spinal cord trauma. Arch Neurol 1978; 35: $78-83$.

3 Fife D, Kraus J. Anatomic location of spinal cord injury: Relationship to the cause of injury. Spine 1986; 11: $2-5$.

4 Jousse AT, Wynne-Jones M, Breithaupt DJ. A follow-up study of life expectancy and mortality in traumatic transverse myelitis. Can Med Assoc J 1968; 98: 770 - 772 .

5 Kraus JF et al. Survival with an acute spinal cord injury. J Chron Dis 1979; 32: 269 - 283.

6 The National SCI Statistical Center. Spinal cord injury: facts and figures at a glance. Birmingham (AL): University of Alabama at Birmingham National Spinal Injury Center; 1998.

7 Krishblum SC, O'Connor KC. Predicting neurologic recovery in traumatic cervical spinal cord injury. Arch Phys Med Rehabil 1998; 79: $1456-1466$.

8 McElhaney JH, Myers BS. Biomechanical aspects of cervical trauma. In: Nahum AM, Melven JW (eds). Accidental injury: Biomechanics and Prevention. Springer-Verlag: New York 1993, pp 311-361.

9 Miller TR et al. Costs of head and neck injury and a benefit-cost analysis of bicycle helmets. In: Levine RS (ed). Head and Neck Injury. Society of Automotive Engineering: New York 1994, pp $211-240$.

10 Hadley MN et al. Axis fractures resulting from motor vehicle accidents. Spine 1986; 11: $861-864$. 
11 Kondziolka D, Schwartz ML, Waters BC, McNeill I. The Sunnybrook neurotrauma assessment record: improving the trauma data collection. J Trauma 1989; 29: 730-735.

12 Walters BC, McNeill I. Improving the record of patient assessment in the trauma room. J Trauma 1990; 30: 398-409.

13 Levine AM, Edwards CC. Treatment of injuries in the C1-C2 complex. Orthop Clin North Am 1986; 17: 31-44.

14 Burke DC, Burley HT, Ungar GH. Data on spinal injuries - Part I. Collection and analysis of 352 consecutive admissions. Austr NZ J Surg 1985; 55: 3-12.

15 Huelke DF, Moffat EA, Mendelsohn RA, Melvin JW. Cervical fractures and fracture dislocations - An overview. SAE transactions, SAE paper \#790131, Society of Automotive Engineers, Inc., 1979; pp 462-468.

16 Macdonald RL et al. Diagnosis of cervical spine injury in motor vehicle crash victims: how many $\mathrm{X}$-rays are enough? J Trauma 1990; 30: $392-397$.

17 Shapiro SA. Management of unilateral locked facet of cervical spine. Neurosurgery 1993; 33: 832 - 837 .

18 Kewalramani LS, Orth MS, Taylor RG. Injuries to the cervical spine from diving accidents. J Trauma 1975; 15: 130-142.

19 McElhaney J, Snyder RG, States JD, Gabrielsen MA Biomechanical analysis of swimming pool neck injuries. Proceedings of the 23rd Stapp Car Crash Conference, SAE paper \#790137, 1979

20 Shields CL, Fox JM, Stauffer ES. Cervical cord injuries in sports. Physician and Sportsmedicine 1978; 6: $71-76$.

21 Portnoy HD, McElhaney JH, Melvin JW, Croissant PD Mechanism of cervical spine injury in auto accidents. Proceedings of the 15th Conference of the American Association for Automotive Medicine 1972, pp 58-83.
22 Yoganandan $\mathrm{N}$ et al. Epidemiology and Injury Biomechanics of Motor vehicle related trauma to the human spine. Proceedings of the 33rd Stapp Car Crash Conference, SAE paper \#892438, 1989; pp $223-224$

23 Montane I, Eismont FJ, Green BA. Traumatic occipitoatlantal dislocation. Spine 1991; 16: $112-116$

24 Ryan MD, Henderson JJ. The epidemiology of fractures and fracture-dislocations of the cervical spine. Injury 1992; 23: 38 40.

25 Alker GJ, Oh YS, Leslie EV. High cervical spine and craniocervical junction injuries in fatal traffic accidents: A radiological study. Orthop Clin North Am 1978; 9: 1003 - 1010.

26 Bucholz RW, Burkhead WZ, Graham W, Petty C. Occult cervical spine injuries in fatal traffic accidents. J Trauma 1979; 19: 768 771.

27 Go BK, DeVivo MJ, Richards JS. The epidemiology of spinal cord injury. In: Stover SI, DeLisa JA, Whiteneck GG (eds). spinal cord injury: Clinical outcomes from the model systems. Aspen publishers: Gaithersburg, MD 1995, pp 21-51.

28 Burney RE, Maio RF, Maynard F, Karunas R. Incidence, characteristics and outcome of spinal cord injury at trauma centers in North America. Arch Surg 1992; 128: 596-599.

29 Saboe LA et al. Spine trauma and associated injuries. J Trauma 1991; 31: $43-48$

30 Vallet G, Ramet M. Frequency and severity of head and neck injuries as a function of types of traffic users. In: IRCOBI/AAAM Conference on the Biomechanics of Impacts. Goteborg, Sweden, $1985, \mathrm{p} 71$

31 Huelke DF, Machay GM, Morris A. Vertebral column injuries and lap-shoulder belts. J Trauma 1995; 38: 547-556. 